\title{
A Potência da linguagem simbólica ${ }^{1}$
}

\author{
El poder del lenguaje simbólico
}

\section{The power of symbolic language}

\author{
Liliana Magalhães ${ }^{2}$
}

Palavras chave:

Mentalidade

Gestão

Processos

Diálogo

Setor produtivo

\section{Resumo:}

A relação entre o avanço do papel das instituições culturais no país, especificamente dos centros culturais e museus, e o amadurecimento das práticas de gestão cultural é abordada a partir do questionamento sobre como essas práticas têm se desenvolvido no sentido de ativar os arranjos criativos e o desenvolvimento local. A partir de uma visão sobre o impacto da mentalidade investidora - seus propósitos e objetivos - nos processos de produção das iniciativas culturais nos últimos 20 anos, o artigo desperta para a potência estratégica da cultura e de seu valor simbólico na sociedade do conhecimento diante do desafio de estar em sintonia com as transformações sociais. Ao citar modelos que foram apontando as novas tendências, alerta sobre a urgência de definições mais claras para os papeis, as funções e objetivos dos modelos de gestão agora em voga e para a consequente necessidade de criação de metodologias específicas que sejam capazes de adotar uma atitude de desenvolvimento do setor da economia criativa. Caracteriza as moedas de troca entre o interesse do investidor e a resposta da gestão cultural até agora, desperta para a tendência dos interesses dos agentes transformadores e empreendedores hoje e exemplifica como as qualidades e capacidades da cultura podem responder a essa demanda na conexão com outros setores da sociedade. Apresenta em seguida um conceito de gestão empreendedora com um relato da implantação de uma instituição cultural que estabeleceu suas premissas centradas em promover inovação para própria cidade - pautadas por princípios éticos - resultantes de estudo e investigação permanentes do meio artístico-cultural e em sintonia com as tendências de comportamento, mercado, consumo, mídia e comunidade. Descreve a sequência de providências necessárias a uma atuação própria e legítima de instituição do terceiro setor para ser agente de mudanças. As múltiplas interseções estabelecidas entre os atores sociais permite compreender o fôlego multiplicador do modelo de gestão em parceria adotado e para exemplificar, descreve como uma mostra de arte eletrônica pode ser muito mais que uma iniciativa de exibição de um projeto cultural, pode ser um fio condutor de um movimento cultural de integração e de arranjos criativos. A dinâmica de desenvolvimento é apresentada com enfoque na nova mentalidade criada com as metodologias de gestão da iniciativa, de modo a corresponder às características da produção da arte contemporânea. Os resultados das iniciativas realizadas com os vários setores produtivos são descritos, bem como seus impactos de inovação. Para finalizar, é feita uma reflexão sobre a importância da criação de novos parâmetros e métodos de gestão a partir de uma atitude que potencialize a força transformadora da cultura. 
Resumen:

La relación entre el avance del papel de las instituciones culturales en el país, específicamente los centros culturales y museos, y la maduración de la gestión cultural práctica se aborda desde la cuestión de cómo se han desarrollado estas prácticas para los arreglos creativos y el desarrollo local. A partir de una idea de la repercusión de la mentalidad de los inversores -sus propósitos y objetivos- en los procesos de producción de las iniciativas culturales en los últimos 20 años, el artículo despierta al poder estratégico de la cultura y su valor simbólico en la sociedad del conocimiento frente al desafío de estar en sintonía con las transformaciones sociales. Al citar los modelos que apuntan a las nuevas tendencias advierte sobre la urgencia de definiciones más claras de los roles, funciones y objetivos de los modelos de gestión ahora en boga y la consiguiente necesidad de crear metodologías específicas que son capaces de adoptar una actitud de desarrollo de la economía creativa. Caracteriza la moneda de cambio entre el interés del inversor y la respuesta de la gestión cultural hasta ahora, despertando a la tendencia de los intereses de los procesadores, agentes y empresarios de hoy, ejemplificando cómo las cualidades y habilidades de la cultura pueden responder a esta demanda en relación con otros sectores de la sociedad. A continuación se presenta un concepto de la gestión emprendedora con un relato de la implantación de una institución cultural que ha establecido sus premisas centradas en la promoción de la innovación en la propia ciudad -basada en principios éticos- resultantes de estudios e investigaciones permanentes en el ambiente artístico-cultural y en consonancia con las tendencias de comportamiento, mercado, consumo, medios de comunicación y la comunidad. Describe la secuencia de pasos necesarios a una actuación adecuada y legítima de la institución del tercer sector para convertirse en un agente de cambio. Las múltiples intersecciones entre los actores sociales nos permite comprender el aliento multiplicador de lo modelo de gestión en asociación adoptado y, para ejemplificar, se describe como una muestra del arte electrónico puede ser mucho más que una iniciativa de exhibir un proyecto cultural, puede ser un hilo conductor de un movimiento cultural de integración y de arreglos creativos. La dinámica del desarrollo se presenta con un enfoque en la nueva mentalidad creada con las metodologías para la gestión de la iniciativa con el fin de que coincida con las características de la producción del arte contemporáneo. Los resultados de las iniciativas emprendidas por los diversos sectores productivos se describen, así como su impacto en la innovación. Por último, se hace una discusión sobre la importancia de la creación de nuevas normas y métodos de gestión a partir de una actitud que potencialice el poder transformador de la cultura.
Palabras clave:

Mentalidad

Gestión

Procesos

Diálogo

Sector productivo 


\section{Keywords:}

Mentality

Management

Processes

Dialogues

Productive sector

\section{Abstract:}

The relationship between the advancement of the role of cultural institutions in the country, specifically the cultural centers and museums, and the maturing of practical cultural management is approached from the question of how these practices have been developed to enable the creative arrangements and local development. From an insight into the impact of investor mentality -its purposes and objectives- in the production processes of cultural initiatives in the last 20 years, the article awakens to the strategic power of culture and its symbolic value in the knowledge society facing the challenge being in tune with the social transformations. When citing models that were pointing to new trends, warns about the urgency of clearer definitions for the roles, functions and objectives of management models now in vogue and the consequent need for creating specific methodologies that can be able to promote an attitude to development of the creative economy sector. Characterizes the trading currencies between investor interest and the delivery results of cultural management until now and alert to the tendency of the interests of transformers agents and entrepreneurs today and also shows the examples how the qualities and skills of culture can respond to this demand in connection with other sectors of society. Then presents a concept of entrepreneurial management culture and describes about the implementation of a cultural institution that has your goals focused on promoting innovation from the town itself -based on ethical principles- resulting in permanent study and research of the artistic-cultural environment and in line with the behavioral tendencies, market, consume, media and community. Presents the sequence of steps necessary to a proper and legitimate role of the third sector institutions to be a change agent. The multiple intersections between the social actors allows us to understand the multiplier power of a partnership management model that was adopted and also exemplifies how a exhibition of electronic art can be much more than an initiative of displaying a cultural project, can be a conductor thread of a cultural movement of integration and creative arrangements. The dynamics of development is presented with a focus on new mind set created with the methodologies for managing initiative in order to match the characteristics of the production of contemporary art. The results of the initiatives undertaken with the various productive sectors are described as well as its impacts innovation. Finally, a reflexion discussion is done about the importance of creating new standards and management methods through an attitude that potentiates the transforming power of culture. 


\section{A Potência da linguagem simbólica}

Nos últimos anos muito temos visto no avanço do papel das instituições culturais no país, especificamente com relação aos centros culturais e museus. Pode-se dizer que o amadurecimento das práticas de gestão cultural tem nos evidenciado duas realidades: a de que os processos são os meios para qualificar o desempenho (não mais os projetos), e a de que é fundamental ter foco (afinal!) nos públicos a serem atendidos e não mais apenas nos temas de acervos, memórias e afins.

Nesse ambiente revelam-se modelos que, de alguma forma, também refletem as tendências da gestão em todos os setores produtivos no Brasil e no mundo em busca de dinâmicas que atendam à sede da inovação. O que chama atenção no desenvolvimento do nosso complexo meio produtivo cultural é como essas práticas espelham uma evolução para a qual a gestão cultural precisa estar atenta, se a intenção é ativar os arranjos criativos e o desenvolvimento local. Ao darmos uma olhada rápida para a trajetória dos investimentos na cultura, também ao longo dos últimos anos, vemos na postura do investidor - empresas, governo, setores e pessoas - uma sequência evolutiva que vai da atitude beneficente e assistencialista, passando pela pontual e oportunista até a comercial e criativa e, por fim, se chega à desenvolvedora e participativa. Porém, essa evolução não invalida que todas as atitudes existam ao mesmo tempo e que suas mentalidades, propósitos e objetivos impactem de forma decisiva nos processos, nas maneiras e nos formatos de desenvolvimento das iniciativas culturais todos os dias.
Podemos perceber a lógica dessa evolução apresentando uma síntese dos impactos que caracterizam cada fase na gestão cultural como um espelho desse quadro. A primeira, que se refere à beneficente, subsidia a expressão artística com foco no artista e na sua obra e tende a reforçar a função decorativa e diletante da arte. Portanto, não atende a qualquer processo de produção que consequentemente se vê sob a situação de ser viabilizado a qualquer custo. Essa fase nos leva à velha imagem do artista ou o seu agente com o chapéu na mão. A segunda fase viabiliza ações pontuais com foco na produção do projeto ou produto cultural e é mais voltada à oportunidade, já que serve a fins promocionais do financiador a custo zero com a chegada da lei de incentivos fiscais. Na produção, ela estimula uma disciplina nos papéis e na relação dos envolvidos e na organização de métodos, mas reforça atitudes estanques e ensimesmadas de trabalho. Essa fase nos remete à imagem do produtor com seus projetos atrás de patrocinadores, e esses ainda sem a noção real dos benefícios, participam pelo estímulo do governo com $100 \%$ (cem por cento) de incentivo fiscal. Ou seja, zero de investimento somado à descoberta da visibilidade proporcionada pela experiência da benfeitoria. Já na $3^{\circ}$ fase, que desperta para a característica das relações comerciais, surge o foco nos públicos e com isso a formatação dos bens e serviços passam a demandar novas questões como a identificação do perfil das pessoas, a diversidade de formatos, abordagens e de conteúdos. Essas exigências surgem para alinhar os significados das mensagens e experiências das iniciativas culturais com os atributos de marcas e de produtos, trazendo um consequente aperfeiçoamento nos processos de produção para garantir a qualidade na entrega e o necessário diálogo com os públicos, agora vistos também como consumidores. Aqui, a evolução na produção ou gestão cultural 
acontece com o surgimento dos interesses e ganhos do marketing que impulsionam o relacionamento do investidor para uma relação mais duradoura com os projetos, num período que se caracterizou pela chegada do mecanismo de naming right e das instituições culturais.

Por fim, chegamos a $4^{a}$ fase, quando há o despertar para a compreensão de que a cultura é um setor produtivo e a relação se torna mais atenta à riqueza das trocas e ganhos, a partir de um amadurecimento de diagnóstico, de afinidades, de valores e de objetivos por meio de experiências mais multidisciplinares e Intersetoriais. Nessa fase, há o reconhecimento das responsa- bilidades e dos papéis no desenvolvimento econômico e social (período dos modelos de comissões, editais etc.) e o surgimento da visão de complementariedade de competências para solucionar modelos de operação. Momento também relevante para o entendimento dos importantes impactos das ações culturais na vida das pessoas (educação e consumo) e das cidades. Assim, nascem novos e promissores processos colaborativos de trabalho e gestão. Essa consciência se estabelece de forma gradativa, tanto por parte do investidor, mantenedor ou participante do investimento (crowdfounding), quanto por parte de todos que fazem a cadeia produtiva da economia da cultura.

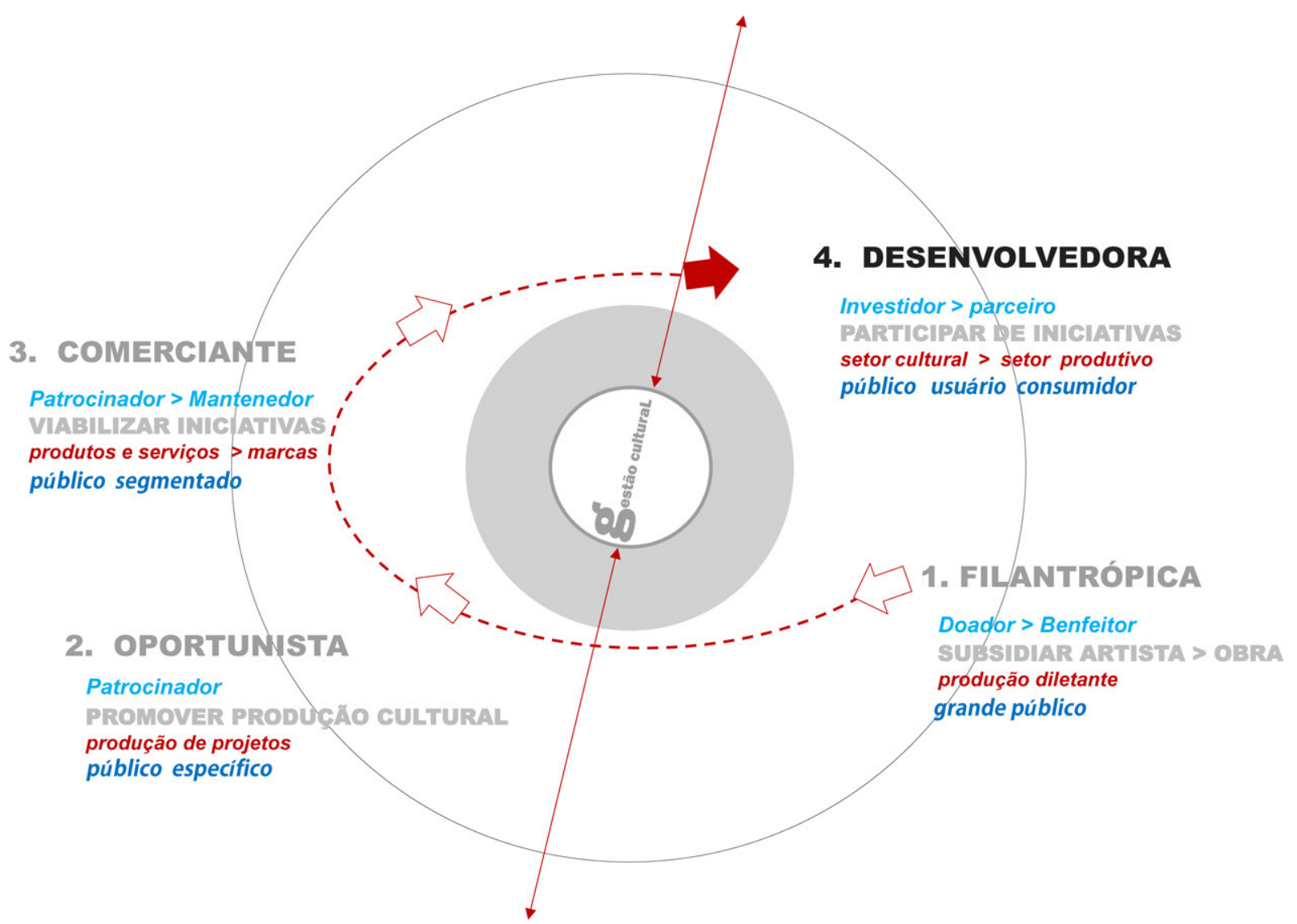

Figura 1 
Sabemos que essas quatro dimensões existem ao mesmo tempo, de forma subliminar e latente nas relações e práticas de gestão e que são naturalmente bastante regidas de acordo com a mentalidade investidora, mas temos que reconhecer que são também estabelecidas pelo grau de sensibilidade, de capacidade e de competência de todos os atores envolvidos no desenvolvimento das iniciativas culturais e das suas percepções de valor dentro do próprio universo cultural. $O$ equilíbrio de forças dentro dessas relações só pode ser estabelecido a partir da tomada de consciência da potência estratégica da cultura e de seu valor simbólico na sociedade do conhecimento. Essa consciência aliada à capacidade de desenvolver novas e criativas formas de atuação são ingredientes decisivos e necessários para o desafio de operar nesse cenário de acirradas transformações com maior co-responsabilidade e em sintonia com os anseios sociais.

Hoje podemos citar modelos que entre outros, foram surgindo, se adaptando e apontando essas tendências. O OI Futuro no Rio de Janeiro, por exemplo, foi implantado com foco em arte e tecnologia e com fomento ao setor cultural, portanto completamente alinhado à área de expertise do investidor/mantenedor que é uma empresa de telecomunicação. Também voltado à educação para o jovem, teve principalmente uma atitude aberta e parceira com o meio cultural e inovou nas metodologias de gestão alimentando inclusive redefinições de política pública. O SESC São Paulo e o Itaú Cultural - que para além de atender aos investidores/mantenedores, respectivamente uma empresa e um setor da economia - desenvolveram um papel fundamental de experimentação da gestão cultural e hoje se caracterizam como escolas e fonte de pesquisa em gestão cultural. Por fim, podemos citar o recente Museu de Arte do Rio, que pratica uma gestão público-privada e se estabelece com um propósito afinado com a formação, com as relações com di- versos públicos e com a arte como meio de conexão com os territórios da cidade.

Diante dos modelos de gestão agora em voga -praticados por organizações sociais como responsáveis pela gestão de instituições públicas, por instituições culturais referenciais do terceiro setor mantidas e geridas pela iniciativa privada, por espaços culturais oferecidos e promovidos através de setores produtivos da economia, como os do sistema $S$, e ainda por museus e espaços criativos geridos por ONGs e por coletivos com apoio público e privado- parece urgente a criação de percepções claras sobre seus papéis, funções e objetivos para consequentemente saber escolher ou criar metodologias para balizar a gestão. Seus desempenhos e os consequentes impactos no meio cultural influenciam e refletem, ao mesmo tempo, em todo o sistema de relações na sociedade.

O que é certo é que a gestão que reforça apenas a exibição e oferta de produtos ou iniciativas culturais, a atração de públicos (às vezes utilizando práticas desastrosas para responder à imposição de volume de visitação) e a busca de geração de visibilidade como moedas de troca, já faz parte de um passado que insiste em se fazer presente, mas seu legado deve ser visto como meio de aprendizagem e superação, não como modelo a ser seguido.

A gestão que promove o diálogo estratégico da cultura com a diversidade das vocações locais adota uma atitude parceira de desenvolvimento do setor da economia criativa e está voltada ao relacionamento com os movimentos sociais e as causas setoriais. Quanto mais legitimidade e interesse coletivo houver na atitude ou no propósito da instituição, maior será o interesse dos agentes transformadores e empreendedores (parceiros, patrocinadores e investidores) em estarem aliados. Afinal é numa relação de afinidade e cumplicidade de ideias, valores e causas que se estabelece uma 
conexão aberta e de compartilhamento. É nesse momento que a cultura, como um bem coletivo, tem as qualidades essenciais de fazer a conexão com outros setores da sociedade e estimular a inovação.

O exercício da gestão cultural ao longo dos anos passa a demonstrá-la como uma ação empreendedora, organizadora, geradora de ideias, processos e bens de caráter multiplicador para o desenvolvimento. Essa definição tem na apresentação da implantação de uma instituição cultural, relatada a seguir, um exemplo prático do surgimento de um modelo novo de gestão cultural.

No início dos anos 2000, uma organização financeira internacional (Grupo Santander) compra bancos com atuação no sul e sudeste do país e decide criar um instituto cultural (Santander Cultural) com sede instalada na cidade de Porto Alegre.
Para além de alinhar seus interesses no fortalecimento da marca e no relacionamento com os públicos por meio do fomento às artes, fatores comumente presentes à época, como os investimentos seriam feitos prioritariamente de forma direta (e não por incentivos fiscais), entrou na pauta um diferencial que exigia novas contrapartidas que justificassem sua atuação.

Essa tarefa foi baseada em algumas premissas básicas como olhar o local com o diálogo global, integrar as diversidades das artes e criar um agente de reconhecimento e representatividade, fazendo com que esse agente, essa instituição, potencializasse as forças da cadeia criativa da cultura e do conhecimento. Mas a estratégia central estava na aposta do diálogo e do envolvimento da cultura com os setores produtivos da sociedade e do governo para promover inovação para própria cidade.

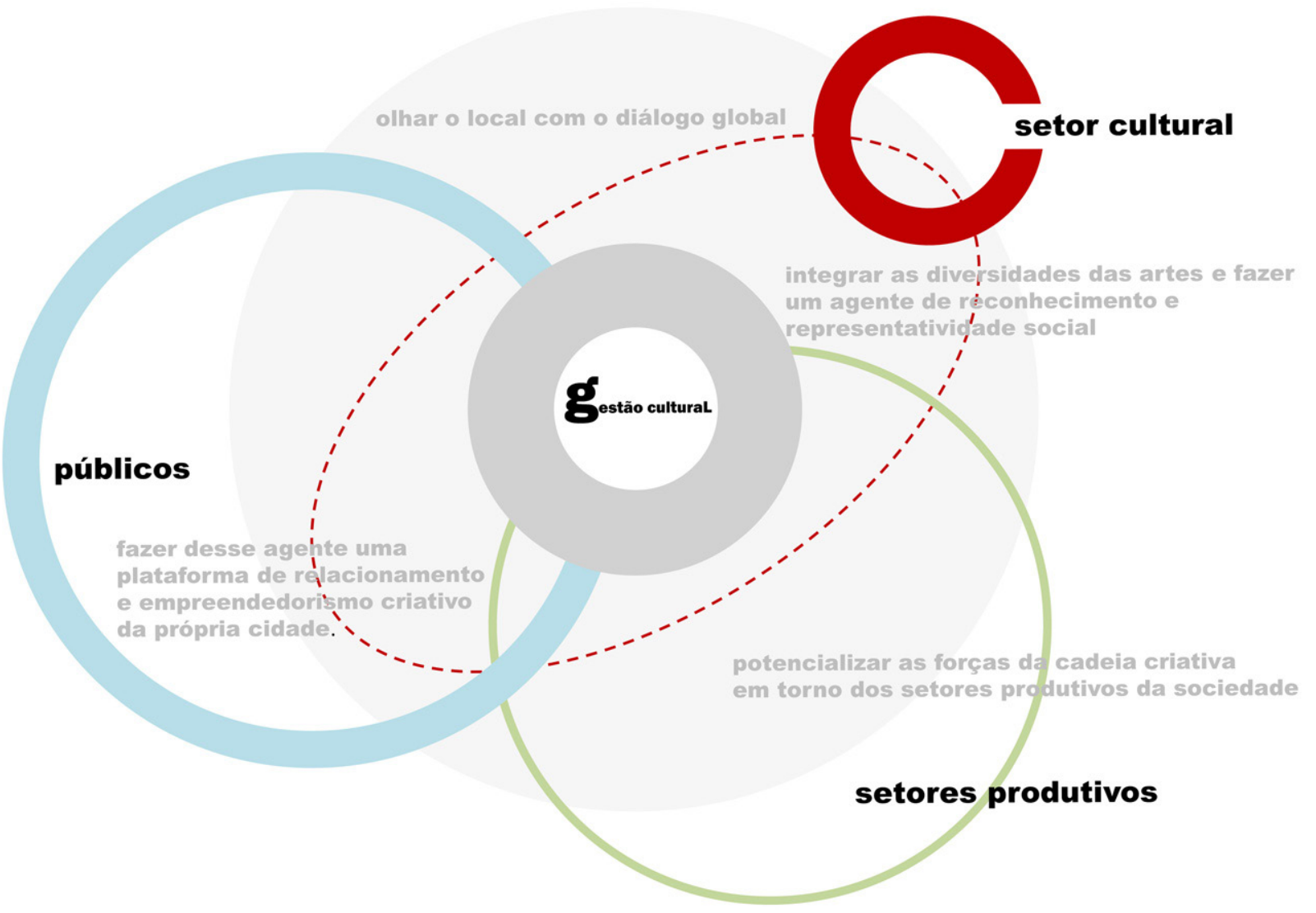

Figura 2 
Diante do desafio, uma questão foi formulada para servir de norte e manter 0 foco e especialmente para a qual todos os esforços deveriam trazer respostas: Como conseguir gerar empreendedorismo e ser agente de mudanças uma vez que se tem de gerar políticas - pautadas por princípios éticos - resultantes de estudo e investigação permanentes do meio artístico-cultural e em sintonia com as tendências de comportamento, mercado, consumo, mídia e da comunidade?

Como numa sequência natural para que essa questão fosse atendida foi necessário criar um modelo de gestão que não replicasse as práticas do investidor e mantenedor (tão bem desenvolvidas para atender a sua natureza privada), mas que tornasse viável uma atuação própria e legítima de instituição do terceiro setor. Essa atuação necessariamente estruturada em parcerias exigiu, numa primeira instância, um grande esforço de entendimento da função da entidade por parte do mantenedor e também das equipes envolvidas na implantação. Foi desse esforço que nasceu o perfil da entidade de se constituir como uma plataforma de relacionamento e integração de parcerias. Para isso, era elementar que sua estrutura, tanto política como operacional, se desse de forma independente, o que configurou a oportunidade de se viver uma experiência em busca de um modelo novo, um modelo associativo de gestão cultural.

Na sequência o objetivo foi de adaptar os processos de governança, administrativos, jurídicos e operacionais para atender à natureza flexível e ágil dos processos criativos, evidenciar o protagonismo dos parceiros e, ao mesmo tempo, marcar o caráter da instituição.

As múltiplas interseções entre os atores sociais, vista no mapa visual abaixo, formou o modelo resultante dessa prática e permitiu a compreensão de concentrar esforços nas parcerias e de manejar a implantação mantendo a gestão fiel e atenta na identificação de expertises locais e globais e na aproximação e no equilíbrio de suas contribuições e protagonismos.

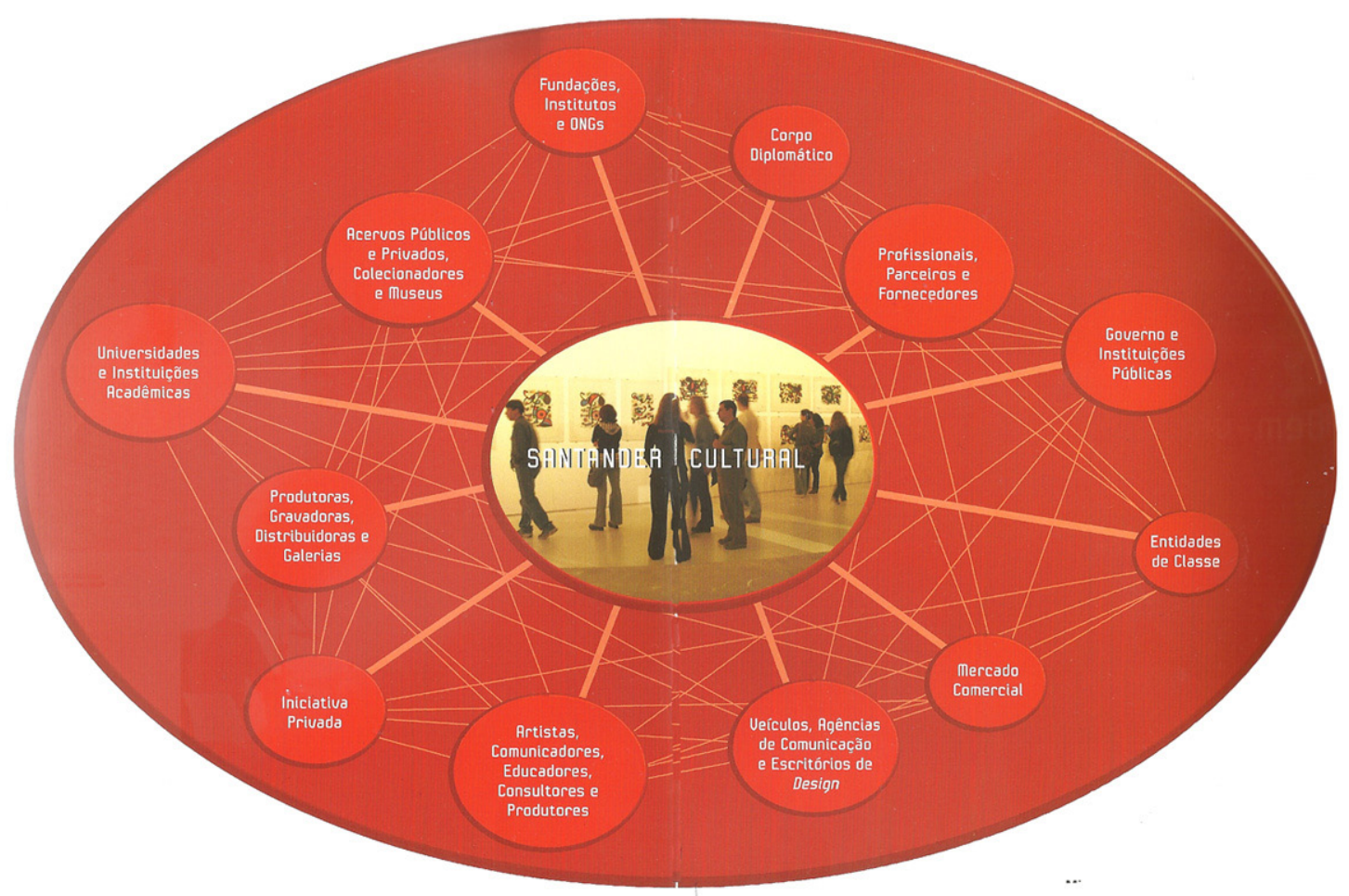

Figura 3 
Dessas interseções resultaram vivências estimulantes que impactavam muitos setores, a partir de seus atores representativos que, instigados, desenvolviam novas ações para agregar reflexão e inovação em seus campos. Vale destacar que no mix de atores do universo cultural se integravam associações e sindicatos da sociedade civil, empresas, governos, instituições, ONGs e coletivos com ênfase nos campos da arte, educação, ciência e tecnologia, mídia, design, arquitetura, economia, marketing, psicanálise e saúde nos setores do comércio, indústria, governo e comunidade.

De forma colaborativa, a gestão desenvolvida na instituição cultural explorava uma linha baseada na soma, nas trocas e na equivalência dos ganhos em permanente observação, pesquisa e análise para formulação de metodologias.

O fôlego dessa linha de gestão se mostrou multiplicador com um crescimento intenso no volume de atividades e públicos, e as variadas soluções desenvolvidas sustentavam a condução do cotidiano revelando sempre novas qualidades no processo. Com o tempo, foi possível contar com ferramentas de gestão especialmente criadas para aferir metas como o volume de parcerias, as iniciativas por elas geradas, a diversidade de áreas de interlocução e de segmento de públicos envolvidos, bem como as contribuições e impactos desse modelo no desenvolvimento socioeconômico.

Para exemplificar esse modo de gerir e de mapear os impactos provocados, descrevemos a seguir um exemplo de como uma mostra de arte eletrônica pode ser muito mais que uma iniciativa de exibição de um projeto cultural. Pode ser um fio condutor de um movimento cultural de ativação, de integração, de arranjos criativos e inovação para um território.

\section{Apresentação de caso}

Com a definição de abordar a arte e tecnologia e a firme orientação de que o processo e os produtos surgidos na iniciativa de fazer a mostra tivessem o foco nas pessoas, o objetivo identificado foi o de despertar vivências e reflexões sobre as múltiplas possibilidades criativas oferecidas pela tecnologia e provocar a percepção de como a sociedade estava se inserindo, voluntariamente ou não, no tempo presente (2004).

A forma de condução para realizar a iniciativa se constituiu em comissões de desenvolvimento de planejamento e gestão, de conteúdo e de iniciativas. Os trabalhos das comissões se desenvolveram simultaneamente e alguns de seus membros participaram das três, formando o núcleo gestor da iniciativa que a definiu como um empreendimento cultural. O termo teve o propósito de romper com as visões estabelecidas sobre a realização de uma mostra de arte e de propor a realização de um movimento criativo e cultural da cidade. O objetivo era de que enquanto os processos de pesquisa e desenvolvimento dos conteúdos (artísticos e de outras áreas de conhecimento) fossem integrados, também houvesse a mobilização das demandas (carências, ofertas, ideias e desejos) dos agentes da cidade e do país, que identificados com o tema central ou os temas análogos, participassem de alguma forma. Ao mesmo tempo, a comissão das iniciativas identificava e conduzia para a realização das ideias que se mostravam pertinentes e viáveis a partir das outras duas comissões.

Juntas essas comissões atuaram de forma interdisciplinar, exigindo de todos os participantes o desapego das formas próprias e predefinidas de trabalhar para co-criar novas dinâmicas provocadas a corresponder com as características da produção da arte contemporânea. Essas características são bem descritas por Ana Mae Barbosa, que sob a perspectiva da arte educação, observa que "a riqueza es- 
tética das hibridizações de códigos e linguagens operadas pela arte hoje é resultado da intensificação da colaboração entre as artes e os meios de produzi-la" (BARBOSA, 2008, p. 23). Portanto, o meio de produção da mostra HIPER foi, da mesma forma, uma intensa experiência híbrida de gestão.

Nesse processo coletivo, surgiu o conceito do empreendimento que a partir da inquietação (como o estado provocado nas pessoas pela velocidade das mudanças que a tecnologia cria) teve como base filosófica para estudos e exploração dos conteúdos o pensamento da hipermodernidade do francês Gilles Lipovetsky (2004).

Sob a ótica de produção de uma mostra de arte contemporânea foi formatado um abrangente panorama das linguagens artísticas proporcionadas pelas inovações tecnológicas e apresentado por um grande elenco de artistas nacionais e internacionais com o título hiPer>relações eletro//digitais. Interativa, a mostra enfocou as relações estéticas e interpessoais, bem como as relações de produção, reunindo ao todo 41 artistas que apresentaram trabalhos utilizando técnicas de cinema e vídeo, multimídia, web instalação, VJ/DJ, música, bioarte, fotografia, arte cinética, plotagem e ciberarte.

A nova poética tecnológica da arte que à época emergia modificava a tradicional percepção autocentrada do processo artístico solitário e demonstrava que - pela soma dos vários e díspares conhecimentos necessários - era possível produzir uma obra de arte de forma coletiva. Essa nova mentalidade foi adotada na gestão da iniciativa, envolvendo questões conceituais e metodológicas, que assim exerceu em sua pluralidade $e$ ação empreendedora no desenvolvimento do projeto em um dinâmico ambiente de rede.

Nessa perspectiva, desenvolver o empreendimento composto pela mostra, e as atividades em torno dela com outros setores produtivos, constituiu-se num laboratório com perfis variados de profissionais como curadores, artistas, gestores, produtores, técnicos, designs, educadores, arquitetos, políticos, comunicadores, empreendedores, urbanistas, filósofos, engenheiros, empresários e claro, muitos especialistas em tecnologia.

Estabeleceram-se conexões com o meio acadêmico, as instituições e os programas da área de ciência e tecnologia, educação e cultura dos governos, com a indústria e os serviços da iniciativa privada e a mobilização das organizações de classe e comunitárias, todos participantes de um fluxo agregador e relacionado ao conceito geral da mostra. Todos envolvidos a partir da ideia de gerar valor, identificando oportunidades de ganho ao formatar atividades paralelas e simultâneas à mostra, conferindo significado, uso e função à arte, atrelando seus saberes e fazeres do cotidiano e dialogando com seus públicos específicos.

Com essa integração de complementariedade de competências e desejos foi gerado um processo intenso de desenvolver bens e serviços que revelou soluções e atendeu a demandas latentes e desconhecidas. Mas foi na experimentação de uma prática de trocas corajosas -que depositava no outro a confiança de encontrar juntos novas soluções e produzir algo novo- que se caracterizaram o aprendizado e os métodos.

O resultado final dessa rede foi criação de um extenso calendário de atividades simultâneas à mostra feito com a parceria e a expertise de 94 parceiros em 21 iniciativas que resultaram em 514 atividades para os mais diversos públicos, especializados e interessados. Nessas atividades oferecidas, um público participante de cerca de 30 mil pessoas se envolveu (MAGALHÃES, 2009, p. 242).

Dentre as inúmeras iniciativas realizadas destacamos algumas criadas especialmente em torno do empreendimento e que podem representar o impacto de inovação nos territórios dos setores produtivos da cidade. 
- Lançamento e Seminário do Ceitec-Amostra foi aberta marcando também o lançamento do Centro Independente de Excelência em Tecnologia Eletrônica do Estado I CEITEC, com um evento oficial e com a realização de um Seminário Internacional que seguiu por três dias após a abertura da mostra. Com forte caráter político empresarial, a abertura contou com a presença do ministro da Ciência e Tecnologia, do Governador do Estado do Rio Grande do Sul, do Secretário da Ciência e Tecnologia do Rio Grande do Sul, do Prefeito da cidade de Porto Alegre e de empresários de diversos setores. Esse lançamento foi articulado e organizado durante as reuniões da comissão de iniciativas da mostra ao lado da equipe do próprio CEITEC com a Secretaria de Tecnologia do Estado, do Ministério da Ciência e Tecnologia e da Financiadora de Estudos e Projetos-FINEP. O seminário envolveu palestrantes da Motorola, da Altus Sistemas de Informação, da América Latina da Advanced Micro Devices (AMD) e da própria FINEP, conferiu a posição de representação de inovação tecnológica do Estado do Rio Grande do Sul, mas também revelou a força articuladora e de diálogo estratégico da arte por ter sido criado a partir das iniciativas de um projeto cultural. É importante revelar que na decisão de organização desse seminário, promovida pela comissão de iniciativas de Hiper (citada acima) com seus parceiros, havia uma meta: a de que em torno dos envolvidos do setor seria debatida e estimulada a viabilidade do investimento necessário para implantação da fábrica que seria o maior centro de produção de chips da América Latina, uma demanda identificada com o setor. Isso ocorreu e a fábrica do CEITEC foi implantada.

\section{- $5^{\circ}$ Fórum do Software Livre PUC} RS /lançamento do License Commons Brasil - hiPerse tornou o lugar de convivências do Fórum, que reuniu 5.000 (cinco mil) internautas, como resultado de uma parceria entre a organização do Fórum, Ministério da Cultura, Fundação Getúlio Vargas- FGV, Associação Software Livre.org, a Prefeitura de
Porto Alegre e as comissões de desenvolvimento de iniciativa da mostra. Entre as inúmeras atividades ocorreu o lançamento do Creative Commons Brasil -a nova modalidade de disponibilização de licenças jurídicas para circulação de bens culturais. A atividade com um show do então Ministro Gilberto Gil contou com a presença de mais de 500 (quinhentas) pessoas, com transmissão simultânea para um público de 2.000 (duas mil) pessoas que se encontravam na praça no entorno do local. A iniciativa de lançamento oficial do Creative Commons Brasil no país teve grande repercussão na mídia e no meio cultural.

- Casa Digital - foi um showroom da Casa do Futuro, apresentando a moradia com serviços e produtos de automação predial. Essa solução criativa surgiu da identificação do problema do setor da construção civil com relação à tecnologia naquele momento. Por meio da soma de esforços da Seta Tecnologia (microempresa formada por jovens empreendedores), a Associação de Arquitetos de Interiores do Rio Grande do Sul, do SINDUSCOM-RS e da comissão de iniciativas da mostra foi criada essa ação com o objetivo de promover o conhecimento e a experiência do público com uma casa digital e os benefícios da automação. O empreendimento envolveu cerca de 90 profissionais diretamente, quatro patrocinadores (Cabosul, Home Systems, Infotec e Melnick Construções), sete empresas/entidades apoiadoras e 35 empresas fornecedoras, todas oriundas do Rio Grande do Sul. A Casa Digital recebeu 5.344 visitantes durante 40 dias e despertou grande interesse para vários segmentos de público. As empresas aproveitaram o espaço para realizar demonstração de seus produtos, conquistar e mobilizar clientes, efetuar vendas e principalmente capacitar as pessoas para os usos e funções inovadoras dos produtos. Uma síntese dos impactos pode ser apresentada com: a promoção da quebra paradigmas sobre a moradia - agregando valor criativo para um setor produtivo normalmente ligado a arte pela arquitetura -, a atração de uma nova gama de público ao local que não iria a um 
centro cultural nem ver uma mostra de arte digital, a oferta de uma experiência criativa ao público que visitava a mostra e despertava para a ligação da arte e da criatividade no cotidiano. E ainda, foi aferido que durante e logo após o período do showroom houve um aquecimento de $40 \%$ nas vendas dos produtos de automação predial de acordo com informações do SINDUSCOM-RS. Por sua vez, o sucesso da iniciativa fez a Seta Tecnologia fazer nascer de vez o produto "Casa do Futuro" e passou a empreendê-lo em outras cidades e estados da região.

- Criação e instalação do $1^{0}$ Telecentro de Inclusão Digital, surgiu por meio da identificação da necessidade da Prefeitura em instalar e operar uma série de centros de inclusão digital em áreas de baixo índice de desenvolvimento humano - idh e com alto ín- dice de criminalidade. A integração de esforços entre a Secretaria de Municipal de Direitos Humanos, a Companhia de Processamento de Dados -Procempa, a Secretaria de Educação, a Fundação Pensamento Digital da UFRGS, o Parque Tecnológico da PUC RS e a área educativa da mostra/instituição criou um modelo para gerir e apoiar a implantação desses centros. Como estratégia de exercício e prática desse modelo, foi instalado o primeiro Telecentro na instituição cultural durante a mostra Hiper que atendeu 4.000 (quatro mil) estudantes e 61 instituições de ensino público. Além de operar como local central para as capacitações e a difusão de métodos a serem aplicados nos demais locais da cidade, o Telecentro se tornou uma atividade permanente na instituição cumprindo uma função inovadora na inclusão digital para vários públicos especiais e da terceira idade.

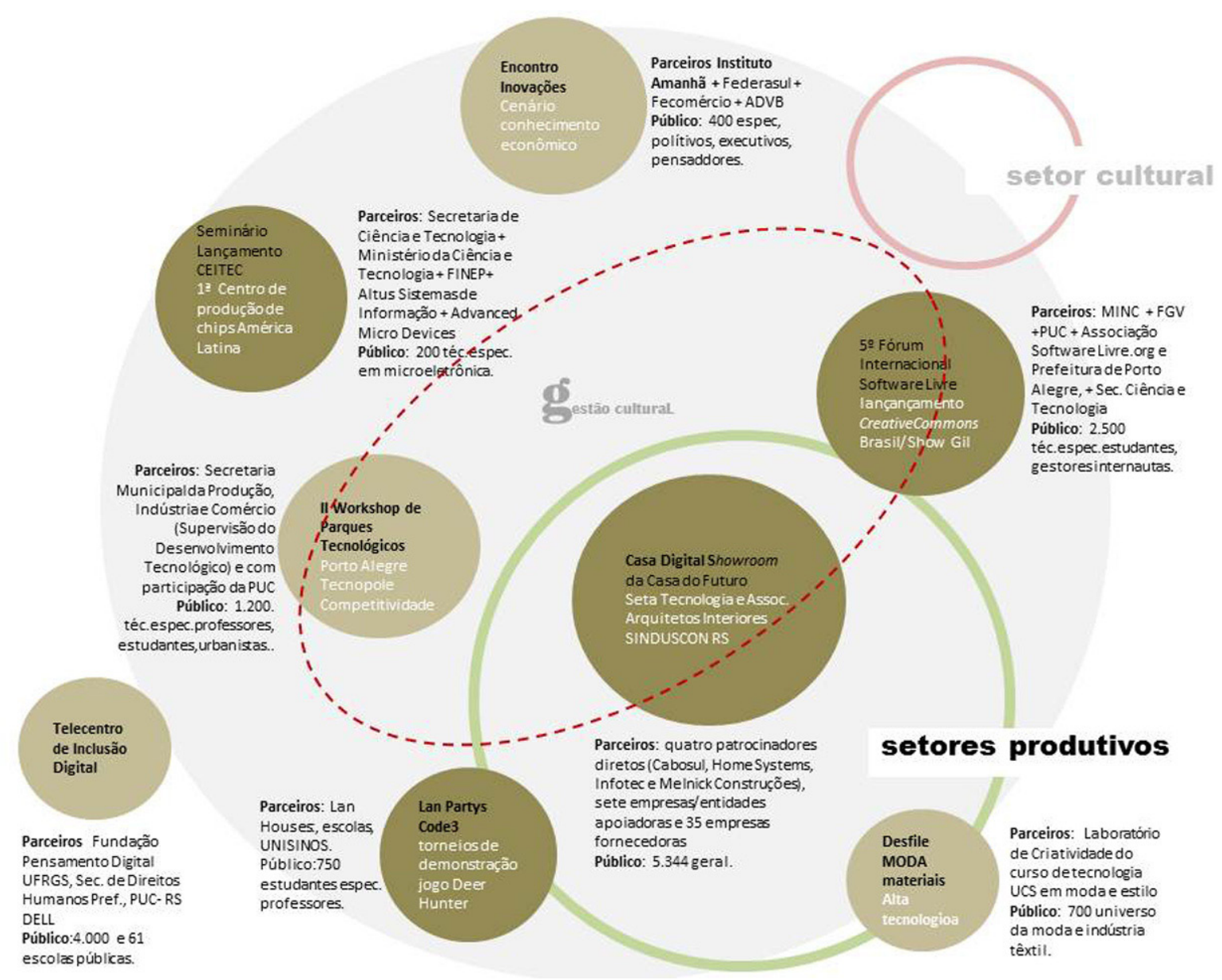

Figura 4 
Para não deixarmos de citar iniciativas mais conhecidas em torno de mostras, vale registrar as inúmeras iniciativas educativas com professores, estudantes, escolas, universidades com a área educativa da mostra (atendeu 15 mil estudantes, 1.500 professores e 400 instituições de ensino) e ainda as Oficinas Digitais promovidas pela Associação Rio-grandense de Artes Plásticas Francisco Lisboa; o Ciclo hiPer, com palestras de artistas e especialistas da arte nas novas mídias, proposto pela curadoria; os Encontros das Inovações, em parceria com o Instituto Amanhã, elucidando os impactos causados pela revolução tecnológica na economia; o Fórum das Inquietações, em parceria com veículos de comunicação, para a troca de ideias com gente que faz; o seminário "A Música Eletrônica em Questão", que discutiu os diferentes aspectos da produção da música eletrônica; as lan houses, que instalaram máquinas de games de última geração para testar produtos promovendo competições entre estudantes e escolas. Essas iniciativas condensaram e difundiram uma profusão de hiperatividades que, durante três meses, geraram conhecimentos, bens e serviços a partir da cidade de Porto Alegre e mobilizaram um público de 94.101 pessoas, numa média diária de quase mil participantes.

Os arranjos criativos estimulados durante esse empreendimento surgiram naturalmente, atendendo a demandas locais, e geraram soluções originais identificadas com os seus valores e competências. Já os processos vividos e registrados pelo núcleo gestor da iniciativa foram fonte para formular as novas metodologias, que ampliadas consolidaram o modelo de gestão associativa da instituição cultural, passando definitivamente a orientar sua governança e administração.

Não cabe aqui elencar os inúmeros impactos e reconhecimentos conquistados com esse modelo de gestão, mais vale destacar a contribuição ímpar na evolução das mentalidades vigentes. A jornada que sustentou por nove anos (2001-2009) a implantação da instituição, com a manutenção dos investimentos de forma direta, pôde experimentar a força da linguagem da arte como impulso para inovação. Uma prática que foi conscientemente desenvolvida para buscar caminhos que fizessem fazer valer os novos paradigmas de uma economia criativa que ainda engatinhava no país.

É sob esse olhar que busca novos parâmetros para atuação que os gestores culturais precisam buscar seus princípios, propósitos e metodologias. É preciso que algo muito caro e inspirador possa conduzir a todos de forma a garantir que as qualidades da ação artística sejam exaltadas e suas características e seus códigos transformadores sejam respeitados nos modelos de gestão a serem criados. Mas é também relevante estarmos atentos ao que nos distingue para saber lidar com os conhecidos e impostos modelos importados, e já ultrapassados, de outras áreas, dos quais ainda somos contaminados e inconscientemente adaptados. Há muito a fazer para diminuir a distância entre o que somos e o que podemos ser na gestão da cultura.

\section{Bibliografia}

BARBOSA, Ana Mae; AMARAL, Lilian (orgs) Interterritorialidade: mídia, contextos e educação. São Paulo: Editora SENAC ; Edições SESC SP, 2008.

LIPOVETSKY, Gilles. Tempos Modernos. São Paulo: Editora Barcarolla, 2004.

MAGALHÃES, Liliana. Marketing Cultural: O que é que eu ganho com isso. In: CRIBARI, Isabela ; REIS, Ana Carla Fonseca (org.). Economia da Cultura. Recife: Fundação Joaquim Nabuco ; Editora Massangana, 2009. p. 231-242.

\section{Fontes das figuras}

Fig. 1, 2.e 4: ilustração de material didático Liliana Magalhães, design gráfico Ado Azevedo. Fig. 3: ilustração do relatório Santander Cultural 2001 / 2006, organizado por Liliana MagaIhães e com design gráfico de Jair de Souza. São Paulo: publicação institucional. 